\title{
Notas sobre o lectótipo de Bothrops cotiara (Gomes, 1913) (Serpentes, Viperidae)
}

\author{
Francisco Luís Franco, Valdir José Germano e Luciana Ribeiro Martão \\ Laboratório de Herpetologia, Instituto Butantan. Av. Vital Brazil, 1500, 05503-900, São Paulo, SP, Brasil. E- \\ mail: flfranco@butantan.gov.br.
}

\begin{abstract}
Keywords: Serpentes, Viperidae, Crotalinae, Bothrops cotiara, taxonomy, lectotype. Palavras-chave: Serpentes, Viperidae, Crotalinae, Bothrops cotiara, taxonomia, lectótipo.
\end{abstract}

Gomes (1913) descreveu Lachesis cotiara baseando-se em três síntipos, procedentes do Núcleo Colonial Cruz Machado, do município de Marechal Mallet, estado do Paraná, Brasil. Cruz Machado é atualmente classificado como município, tendo sido desmembrado do município de Mallet (antigo Marechal Mallet) em 1951. Esses exemplares não estavam tombados na recémcriada Coleção Herpetológica “Alphonse Richard Hoge” do Instituto Butantan (IBSP) e eram numerados na publicação original como espécimes 1,2 e 3.

A coleção do Instituto Butantan teve origem com Vital Brazil, que iniciou um agrupamento de exemplares já no final do século XIX, alguns dos quais foram, posteriormente, incorporados ao acervo da IBSP por João Florêncio Gomes. No acervo organizado por Gomes, os espécimes eram mantidos em vidros com seus respectivos rótulos. Afrânio do Amaral, em 1920, iniciou a numeração e a catalogação desses exemplares, aproveitando cerca de 1000 exemplares da coleção organizada por Gomes, numeração esta mantida ainda hoje. Amaral incorporou dois dos síntipos de Gomes à coleção IBSP com os números IBSP 450 e IBSP 452 correspondendo

Recebido em 29 de março de 2004. Aceito em 29 de setembro de 2005. Distribuído em outubro de 2005. respectivamente aos exemplares 1 e 3 da descrição original. Não há registro do exemplar 2 na referida coleção, sendo considerado perdido.

Ao abordarem Bothrops cotiara (Gomes, 1913), McDiarmid et al. (1999) sugeriram que os síntipos da espécie estão presumivelmente incluídos no acervo da coleção herpetológica do Laboratório de Herpetologia do Instituto Butantan (IBSP), São Paulo, SP, Brazil. Os dois síntipos restantes foram examinados e comparados com a descrição original, tanto com o texto e as tabelas como com os desenhos. Gomes (1913) apenas mencionou que a figura 6 corresponde ao exemplar 1 (IBSP 450), não identificando, porém, qual exemplar deu origem às figuras 1 a 5. A comparação realizada com os síntipos restantes possibilitou aferir que o desenho da figura 1 de Gomes (1913) foi elaborado com base no exemplar 2 da descrição original, exemplar este extraviado. A figura 1 de Gomes (1913) retrata um exemplar com supraoculares não divididas, ao contrário do exemplar 1 (IBSP 450), e supraoculares proporcionalmente maiores, três escamas claras separando as bordas laterais escuras no primeiro acinturamento ântero-posterior do desenho dorsocefálico e a faixa escura nucal mais longa no lado esquerdo, ao contrário do espécime 3 (IBSP 452).

O desenho da figura 2 de Gomes (1913) foi baseado no espécime 1 (IBSP 450), pela correspondência encontrada após a comparação da 
sua folidose com o da figura. Para a confecção da figura 3 de Gomes (1913), foi utilizado o exemplar 2 (extraviado), devido à ausência de um pequeno escudo na confluência dos escudos rostral, nasal e primeiro SL, encontrado nos espécimes 1 e 3 (respectivamente IBSP 450 e 452) e ausente no exemplar 2, como visto na figura 4 de Gomes (1913).

A figura 4 de Gomes (1913) foi baseada no exemplar 2 (extraviado), devido à representação da pré-ocular superior fazendo parte do canthus rostralis, diferentemente dos espécimes 1 e 3 (IBSP 450 e 452), que apresentam uma pequena escama entre a cantal e a supraocular.

A figura 5 de Gomes (1913) foi baseada no exemplar 3 (IBSP 452), pois o espécime 2 (extraviado) apresenta cauda mutilada e o exemplar 1 (IBSP 450) apresenta 51 pares de escamas subcaudais, enquanto o desenho da figura 1 apresenta 47 pares, como encontrado no espécime 3 (IBSP 452).

Hoge e Belluomini (1959), ao descreverem Bothrops fonsecai, tiveram à disposição os exemplares IBSP 450 e 452 de B. cotiara. Eles escolheram o IBSP 452 para figurá-lo, denominando-o de "tipo". Considerando o artigo de Hoge e Belluomini (1959) como a primeira revisão, deve-se considerar o assumido por eles como uma proposta de designação de lectótipo para a referida espécie. O exemplar IBSP 452 respeita todas as exigências do Artigo 74 do International Code of Zoological Nomenclature (International Commission on Zoological Nomenclature 1999) no que se refere à designação de lectótipo, pois ele é um síntipo, foi figurado na descrição original de Gomes (1913, figura 5) e detalhado em Hoge e Belluomini (1959, figuras 3, 4, 5, 6 e 7). Além disso, Hoge e Belluomini (1959), na qualidade de primeiros revisores, referem-se ao exemplar IBSP 452 como "tipo" de B. cotiara.

Deste modo, o espécime IBSP 452 é o lectótipo de Lachesis cotiara Gomes, 1913 (atualmente Bothrops cotiara) e o espécime IBSP 450 é seu paralectótipo.

\section{Bothrops cotiara (Gomes, 1913)}

Lachesis cotiara Gomes, 1913. Ann. Paulistas Med. Cirurg. 1(3): 65-67 (pl. 8, figs. 1-6).

Bothrops cotiara - Amaral, 1925. Contrib. Hervad Inst. Trop. Biol. Med. 2: 64 pp., 16 pl. [primeira combinação da espécie em Bothrops]; Hoge e Belluomini, 1959. Mem. Inst. Butantan 28: 195-206, 1957/58 [designação do lectótipo].

Lectótipo: IB 452 ( $\mathrm{n}^{\circ} 3$ da descrição de Gomes, 1913, figura 5; figuras 3, 4, 5, 6 e 7 de Hoge e Belluomini, 1959). Entregue ao Instituto Butantan pelo Sr. Roberto da Cunha e Silva. Na descrição original, a data de chegada é dada como março de 1913, porém os livros de registros apontam março de 1912, esta última considerada correta.

Localidade-tipo: Cruz Machado (260.' S, 51²0’ W, 940 m), estado do Paraná, Brasil.

Distribuição geográfica: Áreas abertas associadas a florestas com dominância de Araucaria, excetuando as Serras da Mantiqueira e do Mar. No Brasil, é registrada para os estados do Rio Grande do Sul, Santa Catarina, Paraná e extremo sul de São Paulo. Na Argentina, ocorre em Missiones. (Lema 1960a, b, Hoge e Beluomini 1964, Cei 1993, Martins et al. 2002, Giraudo e Scrocchi 2002, Campbell e Lamar 2004).

Diagnose: Bothrops cotiara distingue-se de todas as espécies do gênero pela combinação dos seguintes caracteres: supralabiais 8 ou 9 , sem lacuno-labiais; sub-caudais 34-52 pares; intersupraoculares 10-14; dorsais em 25 a 29 fileiras de escamas no meio do corpo, normalmente 27, com quilhas que tomam todo o comprimento da escama; escamas ventrais 151-173. Ventre de coloração predominantemente preta, faixa negra pós-ocular larga sem formar gancho após a comissura bucal, como ocorre em $B$. fonsecai. Desenho cefálico forma uma "cruz de dois braços” cinza esverdeada, no meio de uma grande mancha marrom muito escura, quase preta, havendo continuidade entre o claro da cruz e a cor de fundo do dorso, cinza esverdeado. (Hoge e Belluomini 1959, 1964, Lema 
1960a, b, Peters e Orejas-Miranda 1970, Campbell e Lamar 2004).

Descrição do lectótipo: IB 452, macho adulto; cabeça triangular com focinho arredondado em vista dorsal; corpo robusto, cauda relativamente curta; comprimento rostro-cloacal $732 \mathrm{~mm}$, comprimento da cauda $120 \mathrm{~mm}$, comprimento da cabeça 37,8 mm. Escamas dorsais da cabeça quilhadas. Rostral subtriangular, pouco mais largo que alto, não visível em vista dorsal. Nasal dividido acima e abaixo da narina; cinco préfoveais; sub-foveais em uma fileira aumentando para duas fileiras de interoculolabiais. Supralabiais $8 / 8$, lacunal não contata a segunda supralabial. Pré-oculares 2/2, pré-ocular superior muito maior que a inferior, alongada, não contribuindo à formação do canthus rostralis; pré-ocular inferior retangular, menor que a superior. Uma escama subocular longa e afilada de ambos os lados; pós-oculares 3/3; infralabiais $11 / 11$, primeiro par de infralabiais contata entre si após a sinfisial, um par de mentonianas mais longas que largas; primeiras três infralabiais contatam as mentonianas. Seis fileiras de gulares entre as infralabiais e a primeira ventral. Um par estreito de internasais contata entre si após a rostral. Dois pares de cantais alongados, o primeiro cerca de três vezes o comprimento do segundo. Supraoculares pequenos, cerca de quatro vezes mais longos que largos; 7 intercantais; 15 intersupraoculares. Escamas dorsais fortemente quilhadas em 27/27/21 fileiras. 152 ventrais. 47 pares de sub-caudais.

Padrão de coloração do exemplar em etanol 70\%: Dorso da cabeça de fundo escuro quase negro, com região central com uma "cruz de dois braços" cinza esverdeada que continua com o padrão de cor do fundo do dorso. Lateralmente há uma larga faixa negra pós-ocular de três fileiras de escamas de altura, que tangencia as supralabiais, seguindo até a articulação quadrado-mandibular, sem dirigir-se para a região gular, portanto, não formando gancho. Ventralmente, a cabeça é branco sujo com duas faixas inconspícuas escuras longitudinais na região gular, entre as infralabiais e primeiras ventrais. $\mathrm{O}$ ventre é predominantemente preto com pequenas manchas brancas nas bases das escamas ventrais. Ventre da cauda predominantemente preto, com pequenas manchas brancas nas áreas de contato mediano entre as escamas. Dorso com cor de fundo cinza levemente esverdeado com uma série de manchas pretas trapezóides opostas ou alternadas. Centro dos trapézios comumente mais claros, com freqüência isolando duas manchas pretas nas bases laterais dos trapézios. Coloração negra do ventre invade algumas escamas paraventrais, formando pequenas manchas escuras de uma ou duas escamas de largura, separadas das seguintes por uma a três escamas (cinzas) de distância, normalmente duas.

Paralectótipo: IB 450 (nº 1 da descrição original de Gomes, 1913, representado pelas figuras 2 e 6). Procedente da localidade-tipo, doado ao Instituto Butantan por Lourenço Aguelli, em fevereiro de 1912. Macho adulto; comprimento rostro-cloacal $785 \mathrm{~mm}$, comprimento da cauda $128 \mathrm{~mm}$, comprimento da cabeça 37,5 mm. Pré-foveais 4. Supralabiais 9/8. Infralabiais 12/12. Duas supraoculares pequenas de cada lado, formadas pela divisão da placa no terço posterior. Internasais separados entre si por uma pequena escama. Um par de cantais de cada lado, sendo que o primeiro tem o dobro do tamanho do segundo. 14 intersupraoculares. Dorsais em 27/27/23 fileiras. 161 ventrais. Subcaudais em 51 pares, escama terminal ausente (provavelmente foi perdida apenas a escama terminal). Padrão de desenho e colorido semelhante ao lectótipo.

\section{Observações}

As medidas tomadas dos exemplares apresentaram pequenas variações em relação à descrição original, devido à diferença no estado de conservação dos exemplares ou mesmo ao fato de Gomes (1913) ter tomado as medidas do animal vivo ou recém-morto. Gomes (1913) atribuiu ao exemplar 1 (IB 450) $750 \mathrm{~mm}$ de comprimento rostro-cloacal e $120 \mathrm{~mm}$ de cauda. 
Os dados aqui obtidos são 785 mm e 128 mm, respectivamente. Os dados tomados por Gomes (1913) do exemplar 3 (IB 452), $732 \mathrm{~mm}$ de comprimento rostro-cloacal e $118 \mathrm{~mm}$ de cauda, são idênticos aos nossos. Gomes (1913) comentou que as intersupraoculares variam de 11 a 14; porém, no lectótipo (IB 452), foram encontradas 15. Gomes (1913) considerou a ocorrência de uma ou duas infraoculares (= suboculares); entretanto, ambos os exemplares examinados apresentam apenas uma infraocular muito longa. Gomes (1913) atribuiu ao exemplar 3 (IB 452) 155 ventrais; porém, as contagens realizadas mostram a presença de 152 ventrais, diferença atribuída à disparidade entre os métodos de contagem. Gomes (1913) deve ter considerado como ventral a escama mais larga que longa, e aqui foi seguida a proposta de Dowling (1951), que considera a primeira ventral a primeira escama mais larga que longa que contata a primeira fileira de escamas dorsais de ambos os lados. Gomes (1913) atribuiu ao exemplar 1 (IB 450) 158 ventrais e 52 subcaudais; entretanto, há 161 ventrais e 51 sub-caudais.

\section{Agradecimentos}

Agradecemos a Hebert Ferrarezzi (Instituto Butantan, São Paulo) e Ulisses Caramaschi (Museu Nacional, Rio de Janeiro) a leitura crítica do manuscrito e ao Programa BIOTA-FAPESP o apoio financeiro.

\section{Referências Bibliográficas}

Amaral, A. 1925. A general consideration of snakes poisoning and observations on Neotropical pitvipers. Contributions to Harvard Institute of Tropical Biology 2: vi +64 pp., 16 pls.

Campbell, J. A. e W. W. Lamar. 2004. The Venomous Reptiles of Western Hemisphere. Vol. I. New York. Cornell University Press. $476+28$ pp.
Cei, J. M. 1993. Reptiles del Noroeste y Nordeste de la Argentina - Herpetofauna de las Selvas Subtropicales, Puna y Pampas. Monografie XIV, Museo Regionale di Scienze Naturali, Torino. 949 pp. + $126 \mathrm{pl}$.

Dowling, H. G. 1951. A proposed standard system of counting ventrals in snakes. British Journal of Herpetology 1: 97-99.

Giraudo A. e G. Scrocchi. 2002. Argentinean snakes: a commented checklist. Smithsonian Herpetological Information Service 132: 1-53.

Gomes, J. F. 1913. Uma nova cobra venenosa do Brasil. Annaes Paulistas de Medicina e Cirurgia 1: 65-67.

Hoge, A. R. e H. E. Belluomini. 1959 (1957/1958). Uma nova espécie de Bothrops do Brasil (Serpentes). Memórias do Instituto Butantan 28: 195-206.

Hoge, A. R. e H. E. Belluomini. 1964 (1960/1962). Notas sobre Bothrops fonsecai Hoge e Belluomini, Bothrops alternatus Duméril, Bibron et Duméril e Bothrops cotiara Gomes. Memórias do Instituto Butantan 30: 97-102.

International Commission on Zoological Nomenclature, 1999. International Code of Zoological Nomenclature. 4th Edition. International Trust for Zoological Nomenclature. Padova, La Garandola. xxix + 306 pp.

Lema, T. 1960a. Notas sobre os répteis do Rio Grande do Sul, V - Sobre a espécie Bothrops cotiara e sua ocorrência no Estado do Rio Grande do Sul (Serpentes: Crotalidae). Iheringia (Zoologia) 13: 110 .

Lema, T. 1960b. Notas sobre os répteis do Rio Grande do Sul, VI - Ampliação da descrição original de Bothrops cotiara (Gomes, 1913) - Serpentes: Crotalidae. Iheringia (Zoologia) 13: 11-19.

Martins, M., O. A. V. Marques e I. Sazima. 2002. Ecological and phylogenetic correlates of feeding habits in neotropical pitvipers of the genus Bothrops. Pp. 307-328 in G. W. Schuett, M. Höggren, M. E. Douglas e H. W. Greene (eds.), Biology of Vipers. Eagle Mountain. Eagle Mountain Publishing.

McDiarmid, R. W., J. A. Campbell e T. A. Touré. 1999. Snake Species of the World - A Taxonomic and Geographic Reference. Vol. 1. Washington D.C. Herpetologists' League. xii +511 pp.

Peters, J. A. e B. Orejas-Miranda. 1970. Catalogue of Neotropical Squamata. Part I, Snakes. United States National Museum Bulletin 297: 1-347 pp. 